\title{
The effect of maternal stress on blastocyst quality depends on maternal physiological status
}

\author{
Žofia Janštová ${ }^{1,2}$, Ján Burkušs , Janka Kubandová $^{1}$, Dušan Fabian ${ }^{1}$, Juraj Koppel ${ }^{1}$ and Štefan Čikošs ${ }^{1}$ \\ ${ }^{1}$ Institute of Animal Physiology, Slovak Academy of Sciences, Šoltésovej 4, 04001 Košice, Slovak Republic \\ ${ }^{2}$ Institute of Biology and Ecology, Faculty of Sciences, P. J. Šafárik University, Košice, Slovak Republic
}

\begin{abstract}
The effect of maternal stress on blastocyst quality, with respect to maternal metabolic status, was investigated in this study. We exposed female mice with different amounts of body fat to restraint stress and examined their blastocyst quality. Blood concentrations of corticosterone, leptin, adiponectin, insulin and glucose were measured in these females. Significantly lower stress-induced corticosterone elevations were observed in females with high and low amounts of body fat, indicating that the stress response was altered in these females. The basal leptin concentrations were significantly higher in females with high amounts of body fat than in females with low amounts of body fat, and stress induced different responses in these two groups of females. Our results showed that maternal stress can significantly increase the proportion of blastocysts that contain dead (apoptotic) cells in females with high and medium amounts of body fat. In females with low amounts of body fat, the proportion of blastocysts containing dead (apoptotic) cells was already increased before the stress exposure, and application of stress did not significantly change this parameter. Our results showed that the effects of maternal stress on early embryos can depend on the actual physiological status of the maternal organism exposed to stress.
\end{abstract}

Key words: Maternal stress - Body fat - Early embryo

\section{Introduction}

The preimplantation period of development (i.e., the period before the implantation of an embryo into the uterus) is one of the most sensitive phases in mammalian ontogeny, and disturbances at this developmental stage can result in poor pregnancy outcomes in humans and animals (Humblot 2001; Nepomnaschy et al. 2006). Preimplantation embryos can sense and adapt to their environment, and maternal nutrition and lifestyle can significantly influence early embryo development (Varghese et al. 2011). Stress and obesity are the most widespread lifestyle diseases in economically developed countries and can be among the reasons for the decline in human fertility. Moreover, there are data indicating that stress and greater amounts of body fat can also impair

Correspondence to: Štefan Čikoš, Institute of Animal Physiology, Slovak Academy of Sciences, Šoltésovej 4, 04001 Košice, Slovak Republic

E-mail: cikos@saske.sk reproductive functions in farm animals (Rutherford et al. 2012; Kubovičová et al. 2013).

Obese women have a high prevalence of infertility, and it has been demonstrated that obesity can contribute to anovulation, a reduced conception rate, a reduced response to fertility treatment, and increased risks of spontaneous miscarriage, preeclampsia and congenital developmental anomalies (reviewed in Jungheim et al. 2012). Experimental results indicate that maternal obesity can influence the very early stages of development, impairing oocyte developmental potential and early embryo development. Several hormones, adipokines and metabolites have been considered to mediate the effects of maternal obesity on early embryo development, but the exact molecular mechanisms remain unknown (Igosheva et al. 2001; Swain et al. 2004; Čikoš et al. 2010; Bermejo-Alvarez et al. 2012; Koningsdorf et al. 2012).

Clinical and epidemiological studies have shown that more than half of pregnant women could suffer from anxiety or depression, and this problem is even more pronounced in obese pregnant women (Faisal-Cury and Rossi Menezes 2007; Bogaerts et al. 2013). The negative effects of prenatal 
stress on embryo development and offspring health have been well documented (reviewed in Vrekoussis et al. 2010), and there are data indicating that stress can even influence oocyte maturation, fertilization, and early embryo development (Donadio et al. 2007; Lee et al. 2008; Mihálik et al. 2011; Zhang et al. 2011). The identification of receptors capable of binding stress mediators in oocytes and preimplantation embryos suggests that the molecules that are involved in the stress response can act directly on oocytes and the cells of early embryos (Čikoš et al. 2007, 2014; Siemieniuch et al. 2010).

In our previous studies we showed that the amount of maternal body fat or maternal restraint stress can significantly affect the quality of oocytes and in vivo developed preimplantation embryos (Burkuš et al. 2013, 2015; Kubandová et al. 2014; Fabian et al. 2015). In this study, we investigated the effect of stress on blastocyst quality in the context of maternal physiological status. We exposed female mice with different amounts of body fat to restraint stress and examined the quality of their blastocysts and the serum concentrations of selected metabolism-related hormones in these females. To our knowledge, this study is the first examining the response of early embryos to maternal stress with respect to the mother's somatic and metabolic status.

\section{Materials and Methods}

\section{Animals and experimental design}

All experiments were performed on female mice of the ICR (CD-1 IGS) strain (Velaz, Prague, Czech Republic) that were maintained under standard conditions (temperature $22 \pm 2^{\circ} \mathrm{C}$, humidity $65 \pm 5 \%, 12: 12$-h light-dark cycle with lights on at 06:00, and free access to food and water). A two-generation dietary model, based on mouse overfeeding during intrauterine and early postnatal life, was used to produce females with different amounts of body fat (Kubandová et al. 2014). Adult (30-35 days old) female mice underwent hormonal synchronization with pregnant mare serum gonadotropin (eCG 5 IU intraperitoneal; Folligon, Intervet International, Boxmeer, Holland), followed 47 hours later by the administration of human chorionic gonadotropin (hCG 4 IU intraperitoneal; Pregnyl, Organon, Oss, Holland) and were mated with males of the same strain overnight. The fertilized mice were randomly divided into experimental and control groups, and they were housed individually in cages. During the gestation (21 days) and lactation periods (from birth to weaning at 21 days) the mothers in the control group were fed a standard pellet diet (M1; Ricmanice, Czech Republic; $3.2 \mathrm{kcal} / \mathrm{g} ; 26.3 \%$ protein, $9.5 \%$ fat, $64.2 \%$ carbohydrate, and $3.8 \%$ cellulose and hemicellulose). The mothers in the experimental group were fed a standard M1 diet that had been suplemented with the high-energy product Ensure Plus (liquid diet containing $1.5 \mathrm{kcal} / \mathrm{ml}, 15 \%$ protein, $28 \%$ fat, and $57 \%$ carbohydrate) ad libitum. After weaning (21 days after birth), the F1 female mice in both groups were fed the standard diet. At day 35 of age, the F1 mice were individually weighed and scanned with an EchoMRI (Whole Body Composition Analyzer, Echo Medical System, Houston, Texas, USA) to evaluate the amount of the body fat (in grams). The percentage of body fat was calculated as body fat $(\mathrm{g}) /$ body weight $(\mathrm{g}) \times 100$. The mice were then divided into three groups according to the percentage of body fat: HF - mice from the experimental group (overfed during intrauterine and early postnatal life) with highly increased body fat $(\geq 11 \%), M F-$ mice from the control group (normally fed during intrauterine and early postnatal life) with a medium amount of body fat (7-8.5\%) and LF - mice from the control group (normally fed during intrauterine and early postnatal life) with low body fat $(\leq 6.5 \%)$.

Spontaneously ovulating female mice of the F1 generation were mated with males for one or more nights. Mating was confirmed by the identification of a vaginal plug every morning at 07:30, and this time was designated day 1 of gravidity (D1). Females from each group (HF, MF and LF) were randomly divided into two sub-groups (on D1), and one sub-group was then exposed to restraint stress during the four-day preimplantation period (the sub-groups of stressed females were designated as HF-S, MF-S, and LF-S).

\section{Restraint stress}

The females in stressed groups were subjected to restraint stress by being individually placed into adjusted and perforated $50 \mathrm{ml}$ plastic tubes (without squeezing or compression). Each animal was isolated in a cell made of cardboard located outside of the animal colony during the stress exposure. Restraint stress was applied three times per day (at 08:00, 12:00, 16:00) for 40 min during the light phase of the day from D1 to D4 of pregnancy (D1-D4). After stress exposure, the mice were returned to their home cage with free access to food and water.

\section{Hormone and glucose measurement}

Blood collected from decapitated mice was centrifuged to obtain serum. The serum was transferred to clean vials and stored at $-80^{\circ} \mathrm{C}$ until the day of assay. The corticosterone, leptin, adiponectin, insulin and glucose levels were measured using commercially available kits (Corticosterone EIA kit, Enzo Life Sciences, NY, USA; Mouse leptin ELISA kit, Mouse adiponectin ELISA kit, and Rat/Mouse Insulin ELISA kit, Millipore, Billerica, MA, USA; Glucose assay kit, Calbiochem, San Diego, CA, USA), according to the manufacturer's instructions. 


\section{Embryo recovery and blastocyst evaluation}

On D4 after fertilization ( $96 \mathrm{~h}$ after plug identification), the embryos were recovered by flushing the oviduct and uterus using flushing-holding medium (FHM) (Lawitts and Biggers 1993) containing $1 \%$ bovine serum albumin (BSA; SigmaAldrich, St. Louis, USA). The collected embryos were subjected to stereomicroscopic evaluation (Nikon SMZ 745T), and blastocysts were selected for further analysis. The quality of the blastocysts (the blastomere number and the number of dead and apoptotic cells) was assessed using morphological fluorescence staining. Immediately after isolation, the blastocysts were stained with propidium iodide (PI; $10 \mu \mathrm{g} / \mathrm{ml}$; Sigma-Aldrich), washed in phosphate-buffered saline (PBS) containing BSA (Sigma-Aldrich), fixed in 4\% paraformaldehyde (Merck, Darmstadt, Germany) in PBS at room temperature for 1 hour, and stored in $1 \%$ paraformaldehyde in PBS at $4^{\circ} \mathrm{C}$. The fixed blastocysts were washed, permeabilized for 1 hour in PBS with $0.5 \%$ Triton X-100 (Sigma-Aldrich), and then washed in PBS. Then, they were incubated in TUNEL (terminal deoxynucleotidyl transferase dUTP nick end labeling) assay reagents (TUNEL In Situ Cell Death Detection Kit; Roche, Penzberg, Germany) for 1 hour at $37^{\circ} \mathrm{C}$ in the dark. After the TUNEL reaction, the embryos were counterstained with Hoechst $33342(10 \mu \mathrm{g} / \mathrm{ml}$ in PBS; Sigma-Aldrich) for 5 minutes at room temperature, washed, mounted on slides with Vectashield (Vector Laboratories, Burlingname, USA), and observed using fluorescence microscope at a magnification of $\times 400$ (BX50 Olympus, Japan). The number of cell nuclei was determined in each blastocyst. Based on the nuclear morphology, the presence of specific DNA fragmentation in the nucleoplasm and PI positivity/negativity, the embryonic cells were classified as: normal (without morphological changes, without TUNEL labeling, without PI inclusion into the nucleoplasm) or dead (showing at least one of the following features: fragmented or condensed nucleus, TUNEL positive labeling or positive PI staining). Dead cells with nuclear fragmentation or condensation and TUNEL positive labeling were classified as apoptotic.

\section{Statistics}

Statistical analysis was performed using GraphPad Prism software (GraphPad Software, Inc., La Jolla, CA, USA). One-way ANOVA and Tukey's post hoc test were used to compare amounts of body fat and body weights, to estimate the blastocyst cell number, and to compare the differences in the hormone and glucose concentrations between all groups of females (Student's $t$-test was also used to compare the concentrations between the stressed and nonstressed groups). Pearson's correlation analysis was used to assess the relationships between the amounts of body fat and the serum adipokine (leptin, adiponectin) concentrations. The standard chi-square test was used to analyze the proportions of blastocysts with and without dead and apoptotic cells. Kruskal-Wallis test followed by Dunn's test was used to estimate the proportion of dead and apoptotic cells in the blastocysts (the Mann-Whitney test was used to compare the differences between the group with highest proportion of dead/apoptotic cells and other groups). Differences of $p<0.05$ were considered significant.

\section{Results}

\section{Somatic parameters of females}

The amounts of body fat and the body weights of the female mice were measured at day 35 of age. The females in the group with the highest amount of body fat (HF) had 11.55 $\pm 0.11 \%$ body fat and weighed $24.3 \pm 0.52 \mathrm{~g}$ on average, the females in the group with a medium amount of body fat (MF) had $7.43 \pm 0.10 \%$ body fat and weighed $18.4 \pm 0.50 \mathrm{~g}$ on average, and the females in the group with a low amount of body fat (LF) had $5.83 \pm 0.074 \%$ body fat and weighed $16.6 \pm 0.36 \mathrm{~g}$ on average. Body fat amounts and body weights of the HF females were significantly higher than those of the MF and LF females. The body fat amounts and body weights of the MF females were significantly higher than those of the LF females (Fig. 1).
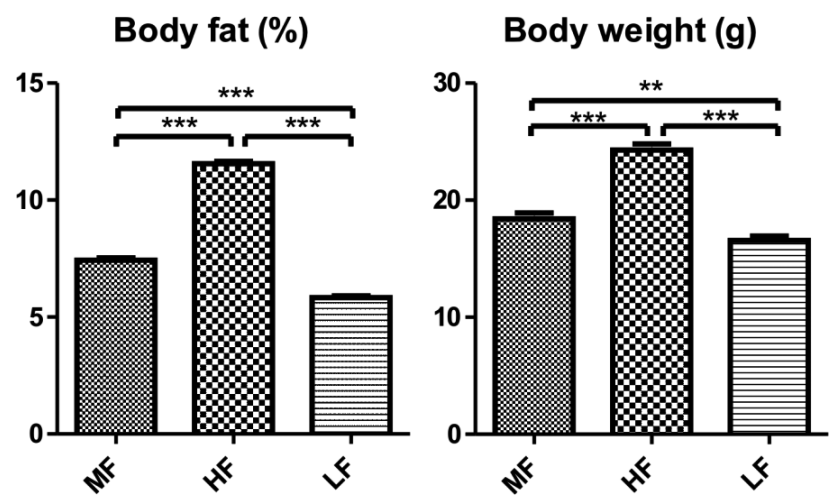

Figure 1. Somatic parameters of females. The body fat amounts and body weights were measured at day 35 of age. MF, females with medium amounts of body fat $(n=25)$; HF, females with high amounts of body fat $(n=19)$; LF, females with low amounts of body fat $(n=34)$. The females from each group were randomly divided into two sub-groups on day 1 (D1) of pregnancy (one sub-group was left intact, and the other was exposed to restraint stress). The values are arithmetic means \pm SEM. One-way ANOVA and Tukey's post hoc test were used to compare the differences between groups of females: ${ }^{* *} p<0.01,{ }^{* *} p<0.001$ 

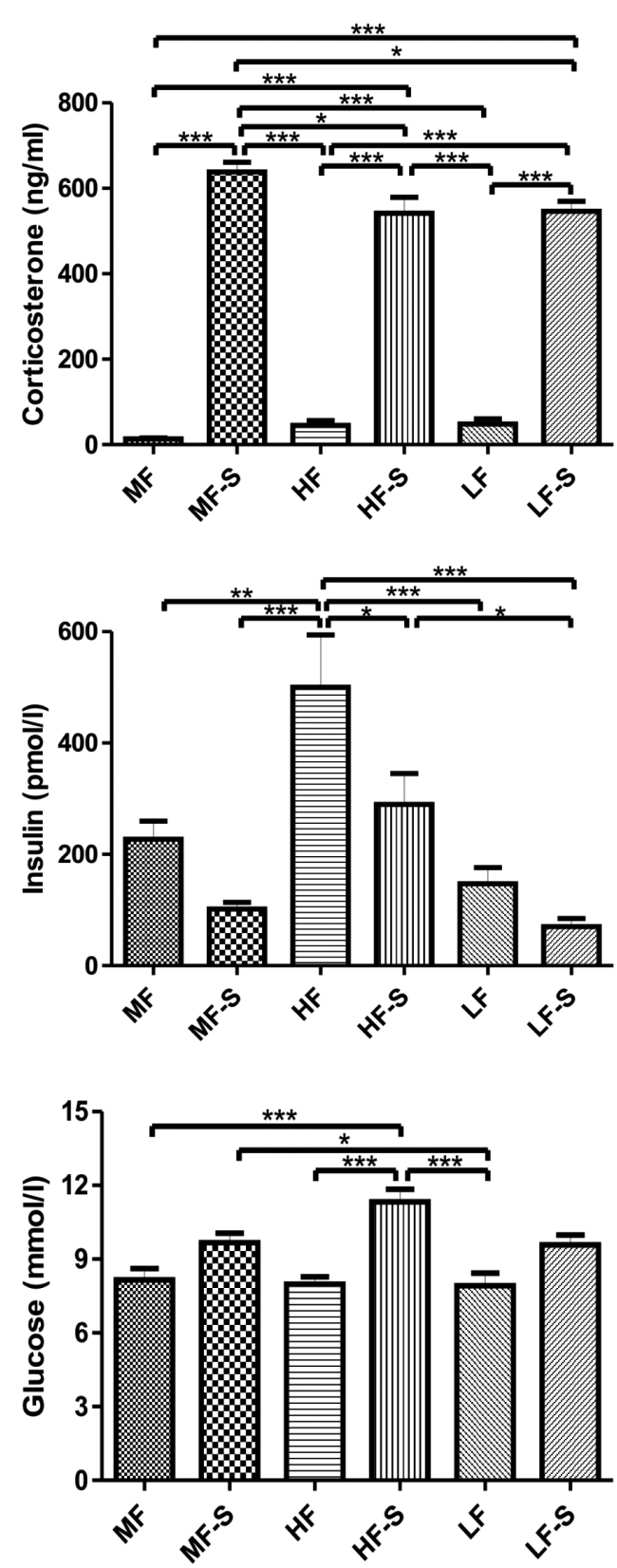

Figure 2. Blood serum corticosterone, insulin and glucose concentrations. The values are arithmetic means \pm SEM (8-12 females per group were analyzed). One-way ANOVA and Tukey's post hoc test were used to compare the differences between all groups of females: ${ }^{\star} p<0.05,{ }^{* *} p<0.01,{ }^{* *} p<0.001$ (comparisons of insulin concentrations between the stressed and nonstressed females with Student's $t$-test: MF vs. MF-S $p=0.0013, \mathrm{LF} v s$. LF-S $p=0.034, \mathrm{HF} v s$. HF-S $p=$ 0.069 ; comparisons of glucose concentrations between stressed and nonstressed females with Student's $t$-test: MF $v s$. MF-S $p=0.019$, LF $v s$. LF-S $p=0.022$, HF $v s$. HF-S $p=0.0001$ ). MF, intact (nonstressed) females with medium amounts of body fat; MF-S, stressed females with medium amounts of body fat; HF, intact (nonstressed) females with high amounts of body fat; HF-S, stressed females with high amounts of body fat; LF, intact (nonstressed) females with low amounts of body fat; LF-S, stressed females with low amounts of body fat.
Serum hormone and glucose concentrations

Significant differences in corticosterone levels were observed between the compared groups of females (ANOVA: $p<0.001$, Fig. 2). We detected moderately elevated basal corticosterone levels in the HF and LF females (45.2 \pm 11.05 and $48.5 \pm 11.6$, respectively) compared with the MF females $(13.7 \pm 2.06, p>0.05)$. The stress-induced serum corticosterone concentrations were significantly higher than the basal levels in all groups of females $(p<0.001)$, and the response was stronger in the MF females (47-fold increase in the average concentration) than in the HF and LF females (12 and 11-fold increases in the average concentrations, respectively). Consequently, the corticosterone levels were significantly higher in the MF-S females than in the HF-S and LF-S females $(p<0.05)$.

Significant differences in the insulin and glucose levels were observed between the compared groups of females (ANOVA: $p<0.001$ for insulin and $p<0.01$ for glucose, Fig. 2). The insulin concentrations were significantly higher in the HF females compared with the MF females (Tukey's post hoc test: $p<0.01$ ) and LF females (Tukey's post hoc test: $p<0.001)$. Stress exposure decreased the insulin concentrations in all groups of females (Tukey's post hoc test revealed a statistically significant difference between the HF and HF-S groups $(p<0.05)$; separate comparisons of the stressed $v s$. nonstressed groups with Student's $t$-test also showed significant differences between the MF and MF-S groups $(p<0.01)$ and between the LF and LF-S groups $(p<0.05))$. The exposure to restraint stress increased the glucose levels in all groups of females; the increase was most prominent in the HF females (Tukey's post hoc test HF vs. HF-S: $p<0.001$; separate comparisons of the stressed $v s$. nonstressed groups with Student's $t$-test also showed significant differences also in the MF vs MF-S $(p<0.05)$ and LF $v s$. LF-S groups $(p<0.05))$.

Significant differences in the leptin levels were observed between the compared groups of females (ANOVA: $p<0.01$, Fig. 3A). We observed the highest leptin concentration in the $\mathrm{HF}$ females and the lowest concentration in the LF females (Tukey's post hoc test HF vs. LF: $p<0.05$ ). The exposure to stress decreased the leptin levels in the MF and HF females (Tukey's post hoc test revealed a statistically significant difference between the HF and HF-S groups $(p<0.05)$; separate comparisons of the stressed vs nonstressed groups with Student's $t$-test also showed significant differences in the MF vs. MF-S groups $(p<0.01))$. In contrast, no decrease was observed in the leptin levels in the stressed LF females. The correlation analysis showed a significant positive relationship (Pearson's $r=0.51, p=0.0102$ ) between the body fat amount and the leptin concentration in nonstressed females, and this positive correlation was abolished (and even reversed) in the stressed females (Pearson's $r=-0.14, p=0.52$, Fig. 3B). 
A

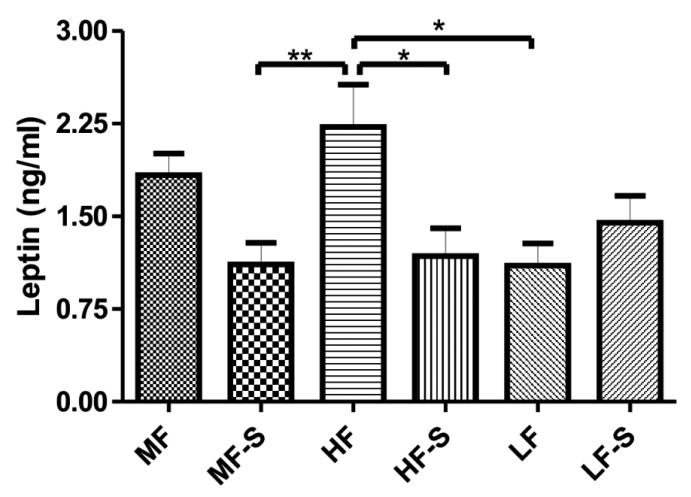

B
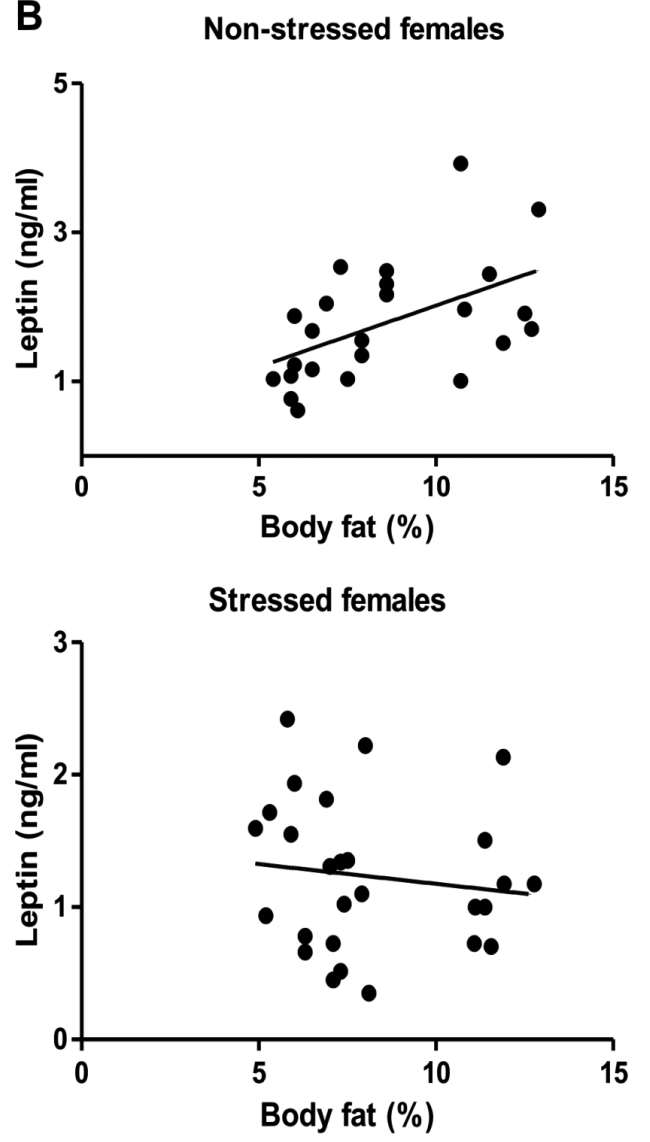

Figure 3. Leptin concentrations and the correlation between the body fat amount and leptin concentrations. A. Blood serum leptin concentrations. The values are arithmetic means \pm SEM (8-12 females per group were analyzed). One-way ANOVA and Tukey's post hoc test were used to compare the differences between all groups of females: ${ }^{\star} p<0.05,{ }^{* *} p<0.01,{ }^{* *} p<0.001$ (comparisons of leptin concentrations between the stressed and nonstressed females with Student's $t$-test: MF $v s$. MF-S $p=0.0089, \mathrm{LF} v s$. LF-S $p=$ 0.26 , HF $v s$. HF-S $p=0.036$ ). B. Relationship between the amounts body fat and leptin serum concentrations in the nonstressed females (Pearson's $r=0.514, p=0.0102$ ) and stressed females (Pearson's $r=$ $-0.14, p=0.52$ ). For abbreviations, see Fig. 2 .
We did not detect significant differences in the adiponectin levels between the compared groups of females (data not shown). The correlation analysis showed only a weak negative relationship between the body fat amount and the adiponectin concentration in the intact (Pearson's $\mathrm{r}=$ $-0.20, p=0.33$ ) and stressed females (Pearson's $r=-0.19$, $p=0.31)$.

\section{Blastocyst quality}

The fluorescence analysis of the blastocysts showed that the numbers of blastomeres were not significantly different between the blastocysts isolated from the examined groups of females (MF 44.4 \pm 1.46 , MF-S 48.1 \pm 1.63 , HF 47.4 \pm 1.90 , HF-S $47.7 \pm 1.08$, LF $44.1 \pm 1.12$, and LF-S $45.0 \pm 1.29$ ).

A comparison of the numbers of blastocysts containing dead cells with the numbers of blastocysts that did not contain any dead cells revealed significant differences between the groups of females (Fig. 4). In the group of females with large amounts of body fat, we observed a significantly higher proportion of blastocysts with dead cells in stressed mothers (HF-S, 53.5\%) than in intact mothers (HF, 30.6\%; $p=0.0035)$. In females with medium amounts of body fat, the proportion of blastocysts with dead cells was 39.5\% in stressed mothers (MF-S group) and $24.3 \%$ in intact mothers (MF group), and this difference also reached statistical

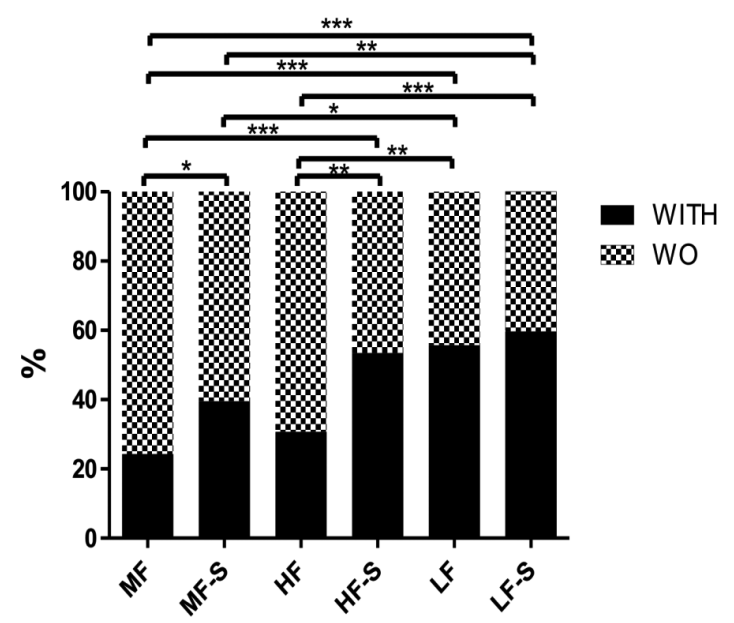

Figure 4. Ratio of blastocysts with and without (wo) dead cells. Blastocysts were obtained from intact (nonstressed) and stressed females with medium amounts of body fat (MF, $n=74$; MF-S, $n=81$ ), from intact (nonstressed) and stressed females with high amounts of body fat (HF, $n=75$; NF-S, $n=86$ ), and from intact (nonstressed) and stressed females with low amounts of body fat (LF, $n=88$; LF-S, $n=114$ ). The percentages of blastocysts containing dead cells and blastocysts that did not contain any dead cells were quantified for each group of females. Differences between groups were estimated using the chi-square test $\left({ }^{*} p<0.05,{ }^{*} p<0.01\right.$, $\left.{ }^{* * *} p<0.001\right)$. For abbreviations, see Fig. 2. 


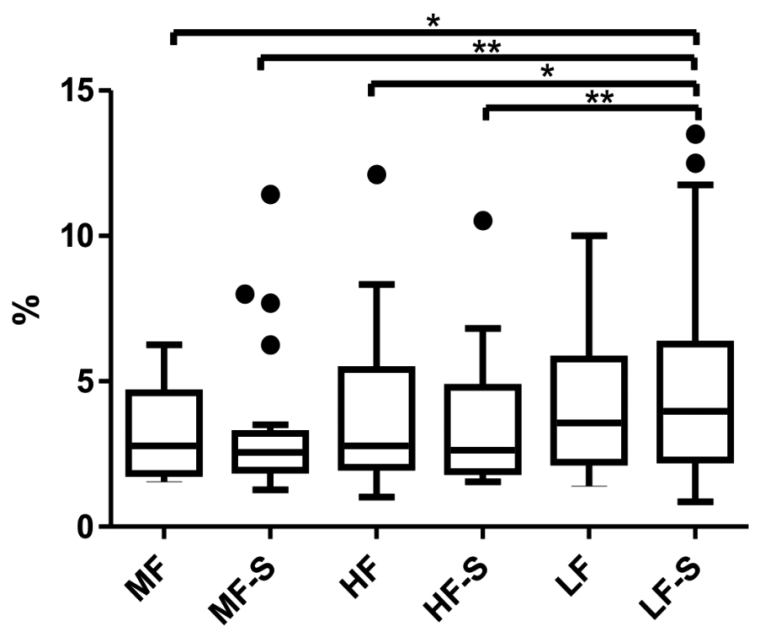

Figure 5. The proportion of dead cells in the blastocysts. Blastocysts were obtained from intact (nonstressed) and stressed females with medium amounts of body fat (MF, $n=74$; MF-S, $n=81$ ), from intact (nonstressed) and stressed females with high amounts of body fat (HF, $n=75$; NF-S, $n=86$ ), and from intact (nonstressed) and stressed females with low amounts of body fat (LF, $n=88$; LF-S, $n=$ 114). The percentage of dead cells was quantified in each blastocyst containing at least one dead cell. The boxes represent the 25th to 75th percentiles, and the horizontal lines within the boxes represent the median values. The whiskers represent the lowest and highest values in the 25 th percentile minus $1.5 \mathrm{IQR}$ (interquartile range) and in the 75th percentile plus $1.5 \mathrm{IQR}$, respectively. The Kruskal-Wallis test was used to estimate differences between all groups $(p<0.05$; Dunn's post hoc test did not reveal significant differences between the individual groups). The LF-S group was compared with the other groups using the Mann-Whitney test: ${ }^{*} p<0.05,{ }^{* *} p<0.01$. For abbreviations, see Fig. 2. significance $(p=0.043)$. No significant difference was observed in mothers with low amounts of body fat between the stressed and intact females (LF-S 59.6\% vs. LF 55.7\%; $p=0.57)$. A comparison of the intact females showed that there were significantly higher proportions of blastocysts with dead cells in mothers with low amounts of body fat than in mothers with medium or high amounts of body fat (LF vs. MF: $p=0.0001$, LF vs. HF: $p=0.0013$ ). A comparison of the stressed females indicated that mothers with medium amounts of body fat had a lower proportion of blastocysts with dead cells than mothers with low and high amounts of body fat (MF-S $v s$. LF-S $p=0.0056$; MF-S $v s$. HF-S $p=$ 0.070).

An analysis of the blastocysts that contained dead cells revealed significant differences in the proportions of dead cells per blastocyst between the compared groups of females (Kruskal-Wallis $p<0.05$, Dunn's post hoc test did not reveal significant differences between individual groups, Fig. 5). The highest proportion of dead cells per blastocyst was observed in the stressed females with low amounts of body fat (LF-S group). A comparison of the differences between the LF-S group and the other groups showed that there were significantly reduced proportions of dead cells per blastocyst in the MF, MF-S, HF and HF-S females (Mann-Whitney test: LF-S vs. MF $p<0.05$, LF-S $v s$. MF-S $p<0.01$, LF-S vs. HF $p<0.05$, and LF-S $v s$. HF-S $p<0.01)$. The proportion of dead cells per blastocyst was only slightly lower in the blastocysts isolated from the LF females than in the blastocyst isolated from the LF-S females (Fig. 5). An evaluation of the apoptotic cells in the blastocysts showed results that were very similar to those obtained for the dead cells. The
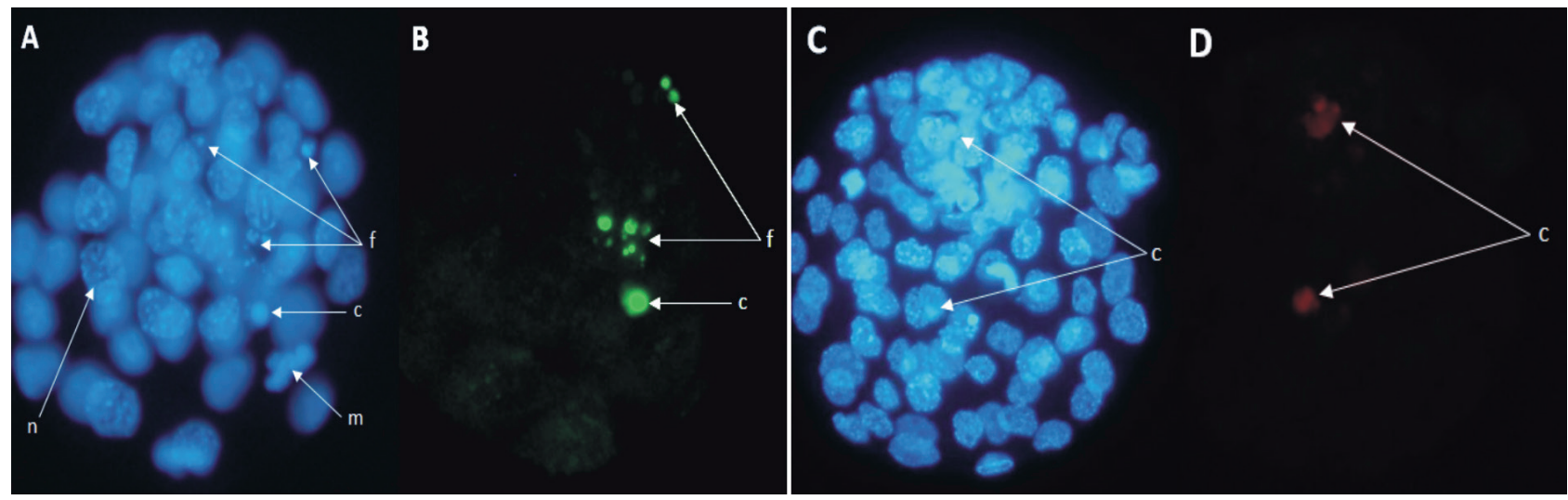

Figure 6. Fluorescence micrographs of mouse blastocysts with apoptotic cells. Apoptosis is characterized by specific morphological features. The cell shrinks and condenses, the nuclear envelope disassembles, and the nuclear DNA fragments. A. Hoechst 33342 staining (blue) showing the nuclear morphology. B. TUNEL (T, Terminal deoxynucleotidyl transferase dUTP nick end labeling) labeling (green) showing specific DNA degradation in the nucleoplasm of apoptotic cells (the same embryo is shown in A and B). C. Hoechst 33342 staining (blue) showing the nuclear morphology. D. Propidium iodide chromatin staining (red) showing the status of the nuclear envelope integrity in the dying cells (the same embryo is shown in $\mathrm{C}$ and $\mathrm{D}$ ). $\mathrm{n}$, normal nucleus; $\mathrm{f}$, fragmented nucleus; $\mathrm{c}$, condensed nucleus; $m$, metaphase. 
propotion of blastocysts with apoptotic cells: MF 24.32\%, MF-S 39.51\%, HF 30.67\%, HF-S 53.49\%, LF 55.68\%, LF-S $59.65 \%$. The proportion of apoptotic cells in the blastocysts (median values): MF 24.32\%, MF-S 39.51\%, HF 30.67\%, HF-S 53.49\%, LF 55.68\%, LF-S 59.65\%. The micrographs illustrate the observed morphological features of the apoptotic cells in the mouse blastocysts (Fig. 6).

\section{Discussion}

To ascertain whether differences in maternal physiological status can influence the effect of stress on blastocyst quality, we exposed female mice with different amounts of body fat to restraint stress and analyzed their blastocysts. Our comparison of the ratio of blastocysts with and without dead cells showed that stress significantly increased the proportion of blastocysts containing dead cells in females with high amounts of body fat. In contrast, a very weak effect of stress on the ratio between blastocysts with and without dead cells was observed in females with low amounts of body fat. The reason for this difference likely lies in the proportion of blastocysts that contain dead cells in the intact (nonstressed) females. Intact mothers with low amounts of body fat showed a significantly higher proportion of blastocysts with dead cells than mothers with high or medium amounts of body fat. These results indicate that a maternal environment with low body fat can itself increase the proportion of blastocysts with dead cells, and the exposure to stress does not significantly increase this parameter. The proportion of blastocysts containing dead cells did not differ significantly between the intact females with medium and high amounts of body fat, and maternal stress showed a stronger effect on females with high amounts of body fat. Our analysis of the blastocysts containing dead cells showed that these cells predominantly died by apoptosis. We observed similar proportion of dead (apoptotic) cells per blastocyst in mothers (intact and stressed) with medium and high amounts of body fat, and the proportion was significantly increased in stressed mothers with low amounts body fat. Intact mothers with low amounts of body fat only showed a slight decrease in the proportion of dead (apoptotic) cells per blastocyst than their stressed counterparts. These results indicate that the increased proportion of dead (apoptotic) cells observed in the blastocyst isolated from stressed females with low amounts of body fat was mainly caused by the alterations in the maternal environment due to low body fat, and the influence of stress was not significant. In our previous study, we found increased proportion of dead and apoptotic cells per blastocyst in females with both low and high amounts of body fat (Kubandova et al. 2014, intact females with respect to stress were used in the study). The discrepancy between the present and previous results likely arises from the fact that females with higher amount of body fat and blastocysts at later developmental stages were evaluated in the experiment reported by Kubandova et al. (2014). Taken together, our results indicate that in females with medium and high amounts of body fat, maternal stress can increase the proportion of blastocysts that contain dead cells, but the stress does not change the incidence of apoptosis in blastocysts. In females with low amounts of body fat, the proportion of dead cell-containing blastocysts and the incidence of apoptosis in blastocysts were already increased before stress exposure, and stress did not significantly change these parameters.

Several factors can contribute to the control of apoptosis in preimplantation embryos. The results of in vitro experiments have revealed that the addition of reactive oxygen species (ROS) to the culture medium can impair preimplantation development and can increase the incidence of apoptosis (Feugang et al. 2003; Bain et al 2011). The results of in vivo studies have shown that unfavorable maternal conditions can induce oxidative stress in oocytes and early embryos. Igosheva et al. (2010) showed that oocytes and embryos that were exposed to an obese reproductive environment can induce a state of oxidative stress and that the antioxidant capacity of such embryos can be impaired. Moreover, there are data indicating that both obese and low body mass index (BMI) conditions can induce oxidative stress (Higashi et al. 2003), which suggests the possibility that similar mechanisms might be involved in the deterioration of embryos developing in obese and lean mothers alike. Lian et al. (2013) showed increased ROS and decreased glutathione levels in oocytes isolated from stressed female mice and formulated the hypothesis that maternal restraint stress can impair the developmental potential of oocytes by causing oxidative stress. Taken together, the above-mentioned data suggest that impaired antioxidant capacity in embryos developing in obese mothers could be one of the factors increasing the sensitivity of these embryos to maternal stress.

Our analysis of the blastocyst cell number revealed no significant differences between the blastocysts isolated from the compared groups of females. In our previous study (Burkuš et al. 2013), a decreased cell number was observed in the blastocysts isolated from mothers exposed to restraint stress (a heterogenic population of females without any dietetic modeling and with undefined somatic parameters was used in the experiment), and the difference was more prominent in later-stage blastocysts $(p<$ $0.001)$ than in earlier-stage blastocysts $(p<0.05)$. Again, the discrepancy between the results could be caused by the different stages of blastocysts analyzed in the two experiments. Early-stage blastocysts were isolated in the present study (45 blastomeres on average), and later-stage blastocysts (55-65 blastomeres on average) were isolated in the 
study of Burkuš et al. (2013). A comparison of the results from two other studies examining the effects of prolonged maternal restraint stress (24 hours of restraint during the period of oocyte maturation) also showed stronger effects on later-stage blastocysts (41 blastomeres on average) than on early-stage blastocysts (56 blastomeres on average; Zhang et al. 2011; Lian et al. 2013). These results indicate that the negative effect of maternal stress on blastocyst cell number can mainly be detected in later-stage blastocysts. However, the maternal stress-induced changes in the proportion of dead cell-containing blastocysts can already be detected in early blastocysts (particularly under some metabolic conditions of the maternal organism).

A large amount of experimental data on endocrine profiles in obesity is available, although conflicting results have been obtained in relation to stress. For instance, increased, decreased or unchanged basal blood concentrations of glucocorticoids have been observed in obese humans and animals (Kohsaka et al. 2007; Cano et al. 2008; Ghalami et al. 2011; Praveen et al. 2011; Veldhorst et al. 2014). Moreover, increased, decreased or unchanged stress-induced corticosterone levels have been identified in obese rats (Boullu-Ciocca et al. 2005; Sasaki et al. 2013). To characterize the maternal physiological status, we measured the blood concentrations of corticosterone, insulin, adiponectin, leptin and glucose in this study. The exposure to stress strongly elevated the serum corticosterone levels in all three groups of females. However, the increase of corticosterone was smaller in females with high and low amounts of body fat. These results indicate that the responses to stress were altered in females with high or low amounts of body fat. We observed significantly higher insulin concentration in the nonstressed females with high amounts of body fat compared with the nonstressed females with medium and low amounts of body fat. In contrast, the glucose concentrations of the nonstressed females with high amounts of body fat did not differ significantly from the other two nonstressed groups, indicating that insulin resistance developed in females with high amounts of body fat. Insulin resistance with hyperinsulinemia and normoglycemia has been shown in several studies (Chen et al. 1994; Gonzalez et al. 2013). It is well known that stress can reduce insulin secretion by activating the adrenergic and glucocorticoid receptors in pancreatic beta cells (Peterhoff et al. 2003; Davani et al. 2004), and we found decreased insulin concentrations in all three groups of stressed females. Consequently, the serum glucose concentrations were increased in all three groups of stressed females, and the increase was most prominent in females with high amounts of body fat. Both the insulin and glucose levels were moderately higher in the stressed females with high amounts of body fat than in the other two stressed groups, suggesting that restraint stress could intensify the insulin resistance state in females with high amounts of body fat. Li et al. (2013) showed that acute stress can rapidly induce insulin resistance, and our results suggest that individuals with increased amounts of body fat can be more sensitive. Insulin and glucose can significantly influence preimplantation embryo growth and development (for reviews see Heyner 1997; Riley and Moley 2006; Jungheim and Moley 2008). Moreover, several studies showed that insulin and glucose can be involved in the regulation of apoptosis in preimplantation embryos (Herrler et al. 1998; Keim et al. 2001; Augustin et al. 2003), and our results suggest that the altered insulin and glucose levels could be some of the factors by which maternal stress influences cell survival in the early embryo.

When comparing the adipokine levels, we did not detect significant changes in the adiponectin concentrations between the examined groups of females, but we found significant changes in the leptin levels. Several studies have shown that stress can influence the leptin serum levels, but different responses were found depending on the stress model, the stress duration of stress and the species (Patterson-Buckendahl et al. 2007; Jeong et al. 2013; deOliveira et al. 2014; Koelsch et al. 2016). In our experiment, restraint stress decreased the serum leptin concentrations in mothers with high and medium amounts of body fat, but not in mothers with low amounts of body fat. Moreover, stress disturbed the positive correlation between the body fat amount and the leptin concentration. Although conflicting results were obtained in experiments examining the role of leptin in preimplantation embryo development (Kawamura et al. 2002; Fedorcsak and Storeng 2003; Swain et al. 2004; Arias-Alvarez et al. 2011), the importance of leptin in mouse blastocyst implantation is well documented (Yang et al. 2005). Thus, changes in the leptin levels (which differ in females with high and low amounts of body fat) could be another factor mediating the effects of maternal stress on early embryo.

Preimplantation embryos express a variety of receptors, including insulin and insulin-like growth factor receptors, leptin receptors, adiponectin receptors and adrenergic receptors, and in vitro experiments have shown that the activation of these receptors can significantly influence early embryo development (for reviews see Heyner 1997; Kaye 1997; Cervero et al. 2005; Čikoš et al. 2011; Čikoš 2012). In the in vivo context, signaling molecules (receptor ligands) produced by the maternal organism can activate embryonal receptors, and the composition of the "ligand cocktail" can differ in various physiological conditions. Our results showed that the effects of maternal stress on early embryos can depend on the actual physiological status of the maternal organism exposed to stress. The molecular mechanisms underlying these changes are unknown, and further research will be required to reveal the signaling molecules and pathways involved. 
Acknowledgement. We thank Soňa Czikková and Dana Čigašová for providing technical assistance. This work was supported by the Slovak Research and Development Agency (contract No. APVV0815-11), the Slovak Academy of Sciences (contract No. VEGA 2/0039/15), and the Research \& Development Operational Program funded by the ERDF (No. 26220120001 and 26220120043). The authors are members of the COST Action FA1201 Epiconcept: Epigenetics and Periconception Environment.

\section{References}

Arias-Alvarez M., Bermejo-Alvarez P., Gutierrez-Adan A., Rizos D., Lorenzo P. L., Lonergan P. (2011): Effect of leptin supplementation during in vitro oocyte maturation and embryo culture on bovine embryo development and gene expression patterns. Theriogenology 75, 887-896

http://dx.doi.org/10.1016/j.theriogenology.2010.10.031

Augustin R., Pocar P., Wrenzycki C., Niemann H., Fischer B. (2003): Mitogenic and anti-apoptotic activity of insulin on bovine embryos produced in vitro. Reproduction 126, 91-99 http://dx.doi.org/10.1530/rep.0.1260091

Bain N. T., Madan P., Betts D. H. (2011): The early embryo response to intracellular reactive oxygen species is developmentally regulated. Reprod. Fertil. Dev. 23, 561-575 http://dx.doi.org/10.1071/RD10148

Bermejo-Alvarez P., Rosenfeld C. S., Roberts R. M. (2012): Effect of maternal obesity on estrous cyclicity, embryo development and blastocyst gene expression in a mouse model. Hum. Reprod. 27, 3513-3522 http://dx.doi.org/10.1093/humrep/des327

Bogaerts A. F., Devlieger R., Nuyts E., Witters I., Gyselaers W., Guelinckx I., Van den Bergh B. R. (2013): Anxiety and depressed mood in obese pregnant women: a prospective controlled cohort study. Obes. Facts 6, 152-164 http://dx.doi.org/10.1159/000346315

Boullu-Ciocca S., Dutour A., Guillaume V., Achard V., Oliver C., Grino M. (2005): Postnatal diet-induced obesity in rats upregulates systemic and adipose tissue glucocorticoid metabolism during development and in adulthood: its relationship with the metabolic syndrome. Diabetes 54, 197-203 http://dx.doi.org/10.2337/diabetes.54.1.197

Burkuš J., Cikoš S., Fabian D., Kubandová J., Czikková S., Koppel J. (2013): Maternal restraint stress negatively influences growth capacity of preimplantation mouse embryos. Gen. Physiol. Biophys. 32, 129-137 http://dx.doi.org/10.4149/gpb_2013010

Burkuš J., Kačmarová M., Kubandová J., Kokošová N., Fabianová K., Fabian D., Koppel J., Čikoš Š. (2015): Stress exposure during the preimplantation period affects blastocyst lineages and offspring development. J. Reprod. Dev. 61, 325-331 http://dx.doi.org/10.1262/jrd.2015-012

Cano P., Jiménez-Ortega V., Larrad A., Reyes Toso C. F., Cardinali D. P., Esquifino A. I. (2008): Effect of a high-fat diet on 24-h pattern of circulating levels of prolactin, luteinizing hormone, testosterone, corticosterone, thyroid-stimulating hormone and glucose, and pineal melatonin content, in rats. Endocrine 33, 118-125 http://dx.doi.org/10.1007/s12020-008-9066-x

Cervero A., Horcajadas J. A., Domínguez F., Pellicer A., Simón C. (2005): Leptin system in embryo development and implantation: a protein in search of a function. Reprod. Biomed. Online 10, 217-223 http://dx.doi.org/10.1016/S1472-6483(10)60943-1

Chen Ch., Hosokawa H., Bumbalo L. M., Leahy J. L. (1994): Mechanism of compensatory hyperinsulinemia in normoglycemic insulin-resistant spontaneously hypertensive rats Augmented enzymatic activity of glucokinase in $\beta$-cells. J. Clin. Invest. 94, 399-404 http://dx.doi.org/10.1172/JCI117335

Čikoš Š., Rehák P., Czikková S., Veselá J., Koppel J. (2007): Expression of adrenergic receptors in mouse preimplantation embryos and ovulated oocytes. Reproduction 133, 1139-1147 http://dx.doi.org/10.1530/REP-07-0006

Čikoš Š., Burkuš J., Bukovská A., Fabian D., Rehák P., Koppel J. (2010): Expression of adiponectin receptors and effects of adiponectin isoforms in mouse preimplantation embryos. Hum. Reprod. 25, 2247-2255 http://dx.doi.org/10.1093/humrep/deq193

Čikoš Š., Fabian D., Makarevich A. V., Chrenek P., Koppel J. (2011): Biogenic monoamines in preimplantation development. Hum. Reprod. 26, 2296-2305 http://dx.doi.org/10.1093/humrep/der233

Čikoš S. (2012): Adiponectin and its receptors in preimplantation embryo development. Vitam. Horm. 90, 211-238 http://dx.doi.org/10.1016/B978-0-12-398313-8.00009-9

Čikoš Š., Czikková S., Chrenek P., Makarevich A. V., Burkuš J., Janštová Ž., Fabian D., Koppel J. (2014): Expression of adrenergic receptors in bovine and rabbit oocytes and preimplantation embryos. Reprod. Dom. Anim. 19, 92-100 http://dx.doi.org/10.1111/rda.12233

Davani B., Portwood N., Bryzgalova G., Kvist Reimer M., Heiden T., Ostenson C. G., Okret S., Ahren B., Efendic S., Khan A. (2004): Aged transgenic mice with increased glucocorticoid sensitivity in pancreatic $ß$-cells develop diabetes. Diabetes 53, 51-59 http://dx.doi.org/10.2337/diabetes.53.2007.S51

De Oliveira C., Scarabelot V. L., De Souza A., De Oliveira C. M., Medeiros L. F., De Macedo I. C., Marques Filho P. R., Cioato S. G., Caumo W., Torres I. L. (2014): Obesity and chronic stress are able to desynchronize the temporalpattern of serum levels of leptin and triglycerides. Peptides 51, 46-53 http://dx.doi.org/10.1016/j.peptides.2013.10.024

Donadio M. V., Kunrath A., Corezola K. L., Franci C. R., AnselmoFranci J. A., Lucion A. B., Sanvitto G. L. (2007): Effects of acute stress on the day of proestrus on sexual behavior and ovulation in female rats: participation of the angiotensinergic system. Physiol. Behav. 92, 591-600 http://dx.doi.org/10.1016/j.physbeh.2007.05.005

Fabian D., Kubandová J., Čikoš Š., Burkuš J., Fabianová K., Račeková E., Czikková S., Koppel J. (2015): The effect of maternal body condition on in vivo production of zygotes and behavior of delivered offspring in mice. Theriogenology 83, 577-589 http://dx.doi.org/10.1016/j.theriogenology.2014.10.025

Faisal-Cury A., Rossi Menezes P. (2007): Prevalence of anxiety and depression during pregnancy in a private setting sample. Arch. Womens Ment. Health 10, 25-32 
http://dx.doi.org/10.1007/s00737-006-0164-6

Fedorcsák P., Storeng R. (2003): Effects of leptin and leukemia inhibitory factor on preimplantation development and STAT3 signaling of mouse embryos in vitro. Biol. Reprod. 69, $1531-1538$ http://dx.doi.org/10.1095/biolreprod.103.019034

Feugang J. M., Van Langendonckt A., Sayoud H., Rees J. F., Pampfer S., Moens A., Dessy F., Donnay I. (2003): Effect of prooxidant agents added at the morula/blastocyst stage on bovine embryo development, cell death and glutathione content. Zygote 11, $107-118$ http://dx.doi.org/10.1017/S0967199403002144

Ghalami J., Zardooz H., Rostamkhani F., Farrokhi B., Hedayati M. (2011): High-fat diet did not change metabolic response to acute stress in rats. EXCLI Journal 10, 205-217

Gonzalez A., Merino B., Marroquí L., Ñeco P., Magdalena P. A., Caballero-Garrido E., Vieira E., Soriano S., Gomis R., Nadal A., Quesada I. (2013): Insulin hypersecretion in islets from diet-induced hyperinsulinemic obese female mice is associated with several functional adaptations in individual $\beta$-cells. Endocrinology 154, 3515-3524 http://dx.doi.org/10.1210/en.2013-1424

Herrler A., Krusche C. A., Beier H. M. (1998): Insulin and insulinlike growth factor-I promote rabbit blastocyst development and prevent apoptosis. Biol. Rep. 59, 1302V1310 http://dx.doi.org/10.1095/biolreprod59.6.1302

Heyner S. (1997): Growth factors in preimplantation development: role of insulin and insulin-like growth factors. Early Pregnancy $3,153-163$

Higashi Y., Sasaki S., Nakagawa K., Kimura M., Noma K., Sasaki S., Hara K., Matsuura H., Goto C., Oshima T., Chayama K., Yoshizumi M. (2003): Low body mass index is a risk factor for impaired endothelium-dependent vasodilation in humans: role of nitric oxide and oxidative stress. J. Am. Coll. Cardiol. 16, 256-263 http://dx.doi.org/10.1016/S0735-1097(03)00630-2

Humblot P. (2001): Use of pregnancy specific proteins and progesterone assays to monitor pregnancy and determine the timing, frequencies and sources of embryonic mortality in ruminants. Theriogenology 56, 1417-1433 http://dx.doi.org/10.1016/S0093-691X(01)00644-6

Igosheva N., Abramov A. Y., Poston L., Eckert J. J., Fleming T. P., Duchen M. R., McConnell J. (2010): Maternal diet-induced obesity alters mitochondrial activity and redox status in mouse oocytes and zygotes. PLoS One 5, e10074 http://dx.doi.org/10.1371/journal.pone.0010074

Jeong J. Y., Lee D. H., Kang S. S. (2013): Effects of chronic restraint stress on body weight, food intake, and hypothalamic gene expressions in mice. Endocrinol. Metab. 28, 288-296 http://dx.doi.org/10.3803/EnM.2013.28.4.288

Jungheim E. S., Moley K. H. (2008): The impact of type 1 and type 2 diabetes mellitus on the oocyte and the preimplantation embryo. Semin. Reprod. Med. 26, 186-195 http://dx.doi.org/10.1055/s-2008-1042957

Jungheim E. S., Travieso J. L., Carson K. R., Moley K. H. (2012): Obesity and reproductive function. Obstet. Gynecol. Clin. North Am. 39, 479-493 http://dx.doi.org/10.1016/j.ogc.2012.09.002
Kawamura K., Sato N., Fukuda J., Kodama H., Kumagai J., Tanikawa H., Nakamura A., Tanaka T. (2002): Leptin promotes the development of mouse preimplantation embryos in vitro. Endocrinology 143, 1922-1931 http://dx.doi.org/10.1210/endo.143.5.8818

Kaye P. L. (1997): Preimplantation growth factor physiology. Rev. Reprod. 2, 121-127 http://dx.doi.org/10.1530/ror.0.0020121

Keim A. L., Chi M. M. Y., Moley K. H. (2001): Hyperglycemiainduced apoptotic cell death in the mouse blastocyst is dependent on expression of p53. Mol. Reprod. Dev. 60, 214-224 http://dx.doi.org/10.1002/mrd.1080

Koelsch S., Boehlig A., Hohenadel M., Nitsche I., Bauer K., Sack U. (2016): The impact of acute stress on hormones and cytokines, and how their recovery is affected by music-evoked positive mood. Sci. Rep. 6, 23008 http://dx.doi.org/10.1038/srep23008

Kohsaka A., Laposky A. D., Ramsey K. M., Estrada C., Joshu C., Kobayashi Y., Turek F. W., Bass J. (2007): High-fat diet disrupts behavioral and molecular circadian rhythms in mice. Cell Metab. 6, 414-421 http://dx.doi.org/10.1016/j.cmet.2007.09.006

Konigsdorf C. A., Navarrete Santos A., Schmidt J. S., Fischer S., Fischer B. (2012): Expression profile of fatty acid metabolism genes in preimplantation blastocysts of obese and non-obese mice. Obes. Facts 5, 575-586 http://dx.doi.org/10.1159/000342583

Kubandová J., Čikoš Š., Burkuš J., Czikková S., Koppel J., Fabian D. (2014): Amount of maternal body fat significantly affected the quality of isolated mouse preimplantation embryos and slowed down their development. Theriogenology 81, 187-195 http://dx.doi.org/10.1016/j.theriogenology.2013.10.014

Kubovičová E., Makarevič A., Stádnik L., Holásek R., Hegedušová Z. (2013): Effect of body condition and season on the yield and quality of cattle embryos. J. Microbiol. Food Sci. 2, $1426-1435$

Lawitts J. A., Biggers J. D. (1993): Culture of preimplantation embryos. Methods Enzymol. 225, 153-164 http://dx.doi.org/10.1016/0076-6879(93)25012-Q

Lee Y. E., Byun S. K., Shin S., Jang J. Y., Choi B. I., Park D., Jeon J. H., Nahm S. S., Kang J. K., Hwang S. Y. et al. (2008): Effect of maternal restraint stress on fetal development of ICR mice. Exp. Anim. 57, 19-25 http://dx.doi.org/10.1538/expanim.57.19

Li L., Li X., Zhou W., Messina J. L. (2013): Acute psychological stress results in the rapid development of insulin resistance. J. Endocrinol. 217, 175-184 http://dx.doi.org/10.1530/JOE-12-0559

Lian H. Y., Gao Y., Jiao G. Z., Sun M. J., Wu X. F., Wang T. Y., Li H., Tan J. H. (2013): Antioxidant supplementation overcomes the deleterious effects of maternal restraint stress-induced oxidative stress on mouse oocytes. Reproduction 21, 559-568 http://dx.doi.org/10.1530/REP-13-0268

Mihálik J., Mašlanková J., Hodorová I., Ferenc P., Rybárová S., Mareková M. (2011): Relationship between serotonin and norepinephrine levels and the preimplantation embryo development in rat. Bratisl. Lek. Listy 112, 52-57 
Nepomnaschy P. A., Welch K. B., McConnell D. S., Low B. S., Strassmann B. I., England B. G. (2006): Cortisol levels and very early pregnancy loss in humans. Proc. Natl. Acad. Sci. U.S.A. 103, 3938-3942 http://dx.doi.org/10.1073/pnas.0511183103

Patterson-Buckendahl P., Pohorecky L. A., Kvetnansky R. (2007): Differing effects of acute and chronic stressors on plasma osteocalcin and leptin in rats. Stress 10, 163-172 http://dx.doi.org/10.1080/10253890701317601

Peterhoff M., Sieg A., Brede M., Chao C. M., Hein L., Ullrich S. (2003): Inhibition of insulin secretion via distinct signaling pathways in alpha2-adrenoceptor knockout mice. Eur. J. Endocrinol. 149, 343-350 http://dx.doi.org/10.1530/eje.0.1490343

Praveen E. P., Sahoo J. P., Kulshreshtha B., Khurana M. L., Gupta N., Dwivedi S. N., Kumar G., Ammini A. C. (2011): Morning cortisol is lower in obese individuals with normal glucose tolerance. Diabetes Metab. Syndr. Obes. 4, 347-352

Riley J. K., Moley K. H. (2006): Glucose utilization and the PI3-K pathway: mechanisms for cell survival in preimplantation embryos. Reproduction 131, 823-835 http://dx.doi.org/10.1530/rep.1.00645

Rutherford K. M. D., Donald R. D., Arnott G., Rooke J. A., Dixon L., Mehers J., Turnbull J., Lawrence A. B. (2012): Farm animal welfare: assessing risks attributable to the prenatal environment. Animal Welfare 21, 419-429 http://dx.doi.org/10.7120/09627286.21.3.419

Sasaki A., de Vega W. C., St-Cyr S., Pan P., McGowan P. O. (2013): Perinatal high fat diet alters glucocorticoid signaling and anxiety behavior in adulthood. Neuroscience 240, 1-12 http://dx.doi.org/10.1016/j.neuroscience.2013.02.044

Siemieniuch M. J., Majewska M., Takahashi M., Sakatani M., Lukasik K., Okuda K., Skarżyński D. J. (2010): Are glucocorticoids auto-and/or paracrine factors in early bovine embryo development and implantation? Reprod. Biol. 10, 249-256 http://dx.doi.org/10.1016/S1642-431X(12)60045-X
Swain J. E., Dunn R. L., McConnell D., Gonzalez-Martinez J., Smith G. D. (2004): Direct effects of leptin on mouse reproductive function: regulation of follicular, oocyte, and embryo development. Biol. Reprod. 71, 1446-1452 http://dx.doi.org/10.1095/biolreprod.104.033035

Varghese A. C., Ly K. D., Corbin C., Mendiola J., Agarwal A. (2011): Oocyte developmental competence and embryo development: impact of lifestyle and environmental risk factors. Reprod. Biomed. Online 22, 410-420 http://dx.doi.org/10.1016/j.rbmo.2010.11.009

Veldhorst M. A., Noppe G., Jongejan M. H., Kok C. B., Mekic S., Koper J. W., van Rossum E. F., van den Akker E. L. (2014): Increased scalp hair cortisol concentrations in obese children. J. Clin. Endocrinol. Metab. 99, 285-290 http://dx.doi.org/10.1210/jc.2013-2924

Vrekoussis T., Kalantaridou S. N., Mastorakos G., Zoumakis E., Makrigiannakis A., Syrrou M., Lavasidis L. G., Relakis K., Chrousos G. P. (2010): The role of stress in female reproduction and pregnancy: an update. Ann. N. Y. Acad. Sci. 1205, 69-75 http://dx.doi.org/10.1111/j.1749-6632.2010.05686.x

Yang Y. J., Cao Y. J., Bo S. M., Peng S., Liu W. M., Duan E. K. (2006): Leptin-directed embryo implantation: leptin regulates adhesion and outgrowth of mouse blastocysts and receptivity of endometrial epithelial cells. Anim. Reprod. Sci. 92, $155-167$ http://dx.doi.org/10.1016/j.anireprosci.2005.05.019

Zhang S. Y., Wang J. Z., Li J. J., Wei D. L., Sui H. S., Zhang Z. H., Zhou P., Tan J. H. (2011): Maternal restraint stress diminishes the developmental potential of oocytes. Biol. Reprod. 84, 672-681 http://dx.doi.org/10.1095/biolreprod.110.087890

Received: September 7, 2015

Final version accepted: April 29, 2016

First published online: July 22, 2016 